\title{
Predicting shunt failure in children: should the global shunt revision rate be a quality measure?
}

\author{
Nicholas B. Rossi, MD, ${ }^{1}$ Nickalus R. Khan, MD, ${ }^{1}$ Tamekia L. Jones, PhD, ${ }^{2}$ Jacob Lepard, MD, ${ }^{3}$ \\ Joseph H. McAbee, BS, ${ }^{4}$ and Paul Klimo Jr., MD, MPH ${ }^{1,5,6}$ \\ 1Department of Neurosurgery, University of Tennessee Health Science Center; ${ }^{2}$ Departments of Pediatrics and Preventive \\ Medicine, University of Tennessee Health Science Center, Children's Foundation Research Institute; ${ }^{5}$ Semmes-Murphey \\ Neurologic \& Spine Institute; and 'Le Bonheur Neuroscience Institute, Le Bonheur Children's Hospital, Memphis, Tennessee; \\ ${ }^{3}$ Department of Neurosurgery, University of Alabama, Birmingham, Alabama; and ${ }^{4}$ School of Medicine, Wake Forest University, \\ Winston-Salem, North Carolina
}

OBJECTIVE Ventricular shunts for pediatric hydrocephalus continue to be plagued with high failure rates. Reported risk factors for shunt failure are inconsistent and controversial. The raw or global shunt revision rate has been the foundation of several proposed quality metrics. The authors undertook this study to determine risk factors for shunt revision within their own patient population.

METHODS In this single-center retrospective cohort study, a database was created of all ventricular shunt operations performed at the authors' institution from January 1, 2010, through December 2013. For each index shunt surgery, demographic, clinical, and procedural variables were assembled. An "index surgery" was defined as implantation of a new shunt or the revision or augmentation of an existing shunt system. Bivariate analyses were first performed to evaluate individual effects of each independent variable on shunt failure at 90 days and at 180 days. A final multivariate model was chosen for each outcome by using a backward model selection approach.

RESULTS There were 466 patients in the study accounting for 739 unique ("index") operations, for an average of 1.59 procedures per patient. The median age for the cohort at the time of the first shunt surgery was 5 years (range 0-35.7 years), with $53.9 \%$ males. The 90 - and 180 -day shunt failure rates were $24.1 \%$ and $29.9 \%$, respectively. The authors found no variable —-demographic, clinical, or procedural-that predicted shunt failure within 90 or 180 days.

CONCLUSIONS In this study, none of the risk factors that were examined were statistically significant in determining shunt failure within 90 or 180 days. Given the negative findings and the fact that all other risk factors for shunt failure that have been proposed in the literature thus far are beyond the control of the surgeon (i.e., nonmodifiable), the use of an institution's or individual's global shunt revision rate remains questionable and needs further evaluation before being accepted as a quality metric.

http://thejns.org/doi/abs/10.3171/2015.5.PEDS15118

KEY WORDS shunt; revision; rate; quality; metric; hydrocephalus; pediatric

$\mathrm{H}$ YDROCEPHALUS remains the most common problem encountered by pediatric neurosurgeons. Although there is growing interest in the use of choroid plexus cauterization in conjunction with endoscopic third ventriculostomy, ${ }^{33}$ ventricular shunting remains the predominant treatment. Surgeons continue to be frustrated by high revision rates, even with the availability of various valve types, intraoperative image guidance (i.e., ultrasound or electromagnetic stereotaxy), and antibiotic-impregnated shunt systems. . $3,3,11,17,18,20$ For example, a 2008 study us- ing the 32-hospital Pediatric Health Information System (PHIS) administrative database found that $25 \%$ of children required a shunt revision within the first year, and $37 \%$ had a revision within 5 years. ${ }^{4}$ A more recent article published in the Journal of the American Medical Association analyzed 30-day condition-specific pediatric readmission rates at 72 children's hospitals in the US. Readmission rates within 30 days for ventricular shunt-related discharges were $18.5 \%$, which accounted for $6.5 \%$ of all 30 -day pediatric readmission diagnoses. This was second

ABBREVIATIONS HCRN = Hydrocephalus Clinical Research Network; LBCH = Le Bonheur Children's Hospital; PHHP = posthemorrhagic hydrocephalus of prematurity; $\mathrm{RQ}=$ revision quotient; $\mathrm{SMR}=$ standardized malfunction rate.

ACCOMPANYING EDITORIAL See pp 247-248. DOI: 10.3171/2015.6.PEDS15291.

SUBMITTED February 23, 2015. ACCEPTED May 11, 2015.

INCLUDE WHEN CITING Published online November 6, 2015; DOI: 10.3171/2015.5.PEDS15118. 
only to a diagnosis of anemia or neutropenia. ${ }^{5}$ Not surprisingly, the economic impact of shunt surgery is substantial, with estimated costs exceeding 1 billion dollars annually in the US.23

The identification of putative predictors of shunt survival has been an area of active research. ${ }^{5,6,10,19,21,25,29,34}$ In the study by Berry et al., risk factors for shunt revision (initial and multiple) were young age, hospitals with lower shunt surgery volume, and type of hydrocephalus (e.g., obstructive and spina bifida). ${ }^{4}$ Tuli et al. found that age, time interval since last revision, and underlying diagnosis were predictors. ${ }^{34}$ Using 2012 data from the National Surgical Quality Improvement Program-Pediatrics (NSQIP-P), Piatt ${ }^{24}$ found that congenital heart disease was adversely associated with shunt failure without infection, but that neuromuscular disease and age $<1$ year were protective. However, these were univariate associations and stable multivariate models could not be constructed. The literature continues to evolve in identifying new potential risk factors, but is also inconsistent in that some studies identify variables that other studies refute. ${ }^{4,6,10,19,21,25,34}$

Over the last decade-but particularly since passage of the Patient Protection and Affordable Care Act (PPACA) in 2010 - there has been a tremendous focus placed on the creation, implementation, and evaluation of quality measurements or metrics, value, and so-called "pay-for-performance" in medicine. For example, in 2009 the Centers for Medicare and Medicaid Services began withholding payments for "reasonably preventable" conditions, such as certain hospital-acquired infections and pressure ulcers. ${ }^{36}$ Quality metrics are being driven by government and private agencies, as well as by physicians within their medical or surgical subspecialties. ${ }^{7,22}$ As a result, children's hospitals, pediatric neurosurgeons, and shunt surgery have come under scrutiny. $2,24,26$

The revision quotient (RQ), defined as the ratio of the number of CSF shunt revisions to the number of new shunt insertions for a particular neurosurgical practice in a unit of time, has been proposed as a metric. Piatt and Freibott calculated 334 annual RQs for 152 different hospitals, with a median value of 2.53 (range $0.06-10.92$ ). ${ }^{26} \mathrm{Dr}$. Goumnerova and colleagues at Boston Children's Hospital advocate the use of the ventriculoperitoneal shunt malfunction rate, defined as the number of initial shunt procedures in which malfunction occurs within 30 days divided by the total number of initial shunt procedures performed. This metric has been endorsed by the National Quality Forum ([NQF], http://www.qualityforum. org/QPS/0713) and a risk-adjusted standardized malfunction rate (SMR) can be calculated to compare a hospital's performance with other hospitals during a 3-year rolling period. One of the most well-recognized and anticipated ranking is by US News \& World Report. Each year it publishes rankings of children's hospitals, both overall and by specialty. For "Pediatric Neurology and Neurosurgery" in the 2014 survey, full points ( 3 points of a possible 3) were awarded to the institution if it had a 90-day shunt revision rate for new/initial shunts of $<3 \%$ (question $\mathrm{H} 29$ ). Where the $3 \%$ benchmark comes from or how any institution is able to achieve this unrealistically low rate are questions that have not been asked or answered to our knowledge.
None of these quality metrics, whether generated from within our specialty or by outside entities (government or private), have been universally accepted or endorsed by the pediatric neurosurgery community or scrutinized for validity. Furthermore, large multicenter administrative hospital databases have significant inherent deficiencies that limit their use when evaluating a certain neurosurgical disease or procedure and, therefore, the creation of quality measurements that are based on such databases. ${ }^{14} \mathrm{We}$ undertook this study in an effort to do the following: 1) create a database specific for the evaluation of pediatric shunt surgery; 2) use this database to identify predictors of shunt failure; and 3) evaluate our results within the context of existing and proposed shunt surgery quality measurements.

\section{Methods}

\section{Database Creation and Outcomes}

The institutional review board of Le Bonheur Children's Hospital (LBCH) approved this study. In July 2013, work began on creation of our shunt surgery database. We started collecting data from January 1, 2010, and have been updating our database on a quarterly basis since July 2013. All shunt operations from a 4-year period between January 1, 2010, and December 31, 2013 were identified from a prospective internal administrative database maintained by the Neuroscience Institute at LBCH. All nonventricular shunt procedures were excluded, including subdural, arachnoid cyst, syrinx, and lumbar shunt systems. Encounters that were related to but were not definitive ventricular shunt operations were excluded, such as shunt taps, endoscopic procedures (fenestration or third ventriculostomy), external ventricular drain placement, externalization, or complete removal of existing shunt system. An "index surgery" was defined as implantation of a new shunt or revision or augmentation (i.e., addition of another proximal catheter) of an existing shunt system. Thus, each patient within our cohort may have had multiple index procedures. Our primary outcomes were 90- and 180-day shunt revision rates from the index procedure. Follow-up was extended to June 30, 2014, so that we had 90- and 180-day follow-up for all procedures performed through December 2013.

\section{Study Question}

Based on a retrospective cohort study, we sought to answer the following question: what factors or variables are associated with or protective against the probability of shunt failure within 90 and 180 days after the index shunt surgery?

\section{Variables and Definitions}

Table 1 lists all the variables that were collected, with a brief explanation. Each variable was recorded per patient and per procedure. Variables were categorized as demographic, clinical, and procedural. Further clarification of some of these variables will be provided in the remainder of this section.

Etiology of hydrocephalus was based on a review of clinical and radiographic information available at the time of the initial index procedure. The category "Other" includes patients for whom the etiology was unclear or di- 
TABLE 1. Variables within the shunt surgery database

\begin{tabular}{|c|c|}
\hline Variable & Details \\
\hline \multicolumn{2}{|l|}{ Demographic } \\
\hline Age & $\begin{array}{l}\text { 1. Continuous variable } \\
\text { 2. Birth-12 mos, }>12 \text { mos }-5 \mathrm{yrs} \text {, } \\
>5-10 \mathrm{yrs},>10 \mathrm{yrs}\end{array}$ \\
\hline Sex & Male or female \\
\hline Race & Caucasian, African American, or other \\
\hline Payor source & Government or private \\
\hline \multicolumn{2}{|l|}{ Clinical } \\
\hline Etiology of hydrocephalus & $\begin{array}{l}\text { PHHP, neoplastic, spinal dysraphism, } \\
\text { congenital, or other }\end{array}$ \\
\hline Ventricular shunt type & Ventriculoperitoneal, -atrial, or -pleural \\
\hline Proximal catheter location & Frontal, occipital, or both \\
\hline $\begin{array}{l}\text { Functional proximal } \\
\text { catheters }\end{array}$ & No \\
\hline $\begin{array}{l}\text { Slit ventricles at time of } \\
\text { index surgery }\end{array}$ & Yes or no \\
\hline $\begin{array}{l}\text { Prior ventricular shunt } \\
\text { surgeries }\end{array}$ & $\begin{array}{l}\text { No. performed at LBCH or other } \\
\text { institution }\end{array}$ \\
\hline $\begin{array}{l}\text { History of shunt or ven- } \\
\text { tricular infection }\end{array}$ & Yes or no \\
\hline $\begin{array}{l}\text { Index surgery due to } \\
\text { recently treated shunt } \\
\text { infection }\end{array}$ & Yes or no \\
\hline $\begin{array}{l}\text { Index surgery performed } \\
\text { after elective intradural } \\
\text { surgery w/in } 30 \text { days }\end{array}$ & Yes or no \\
\hline \multicolumn{2}{|l|}{ Procedural } \\
\hline Type of index surgery & $\begin{array}{l}\text { New placement, revision (proximal, } \\
\text { distal, complete), or other }\end{array}$ \\
\hline $\begin{array}{l}\text { Intraventricular hemor- } \\
\text { rhage at index surgery }\end{array}$ & Yes or no \\
\hline Image guidance & Ultrasound, stereotactic, or none \\
\hline Primary surgeon & $1-5$ \\
\hline Operative time & Continuous variable \\
\hline
\end{tabular}

agnoses that were low in number, such as posttraumatic or postinfectious hydrocephalus. Proximal catheter location was defined as frontal, occipital (which included parietal or posterior fossa catheters), or both. The number of functional proximal catheters describes the number of connected catheters. In other words, old proximal catheters that were tied off but still in place were not counted. We designated a patient as having slit ventricles if that term or a similar description was used in the operative note or in the history and physical at the time of their index surgery. The number of prior ventricular shunt operations was obtained from the electronic medical records; we recognize that some operations may have been missed if they were performed at institutions other than $\mathrm{LBCH}$ or in the period of time before electronic medical records. The same limitation applies to "History of shunt or ventricular infection." "Index surgery due to recently treated shunt infection" was considered positive if the current procedure was a direct result of a recent infection (e.g., shunt was externalized or removed because of infection and is now being replaced). "Index surgery performed after elective intradural surgery" was considered positive when any elective intradural cranial (e.g., tumor resection) or spinal (e.g., spinal cord detethering) procedure preceded the index shunt operation at our institution or at an outside institution within 30 days.

"Type of index surgery" was based on review of the operative report. "Proximal revision" involved replacement of an existing ventricular catheter. "Distal revision" captured valve change, distal catheter revision, or both. "Complete revision" was replacement of the entire shunt system. The category "Other" included the placement of an additional proximal catheter and procedures that did not fit into the previously defined categories. "Intraventricular hemorrhage at time of index surgery" was recorded as positive if there was any mention of significant blood in the CSF at the time of index surgery, during placement or revision of a proximal catheter, or on immediate postoperative CT scans. Electromagnetically assisted frameless stereotaxy was performed using the StealthStation AxiEM system (Medtronic Navigation). Operative time was calculated from the recorded skin incision time to procedure stop time. The vast majority of operations were performed by 1 of 4 pediatric neurosurgeons.

\section{Statistical Analysis}

Patient demographic, clinical, and procedural characteristics were summarized using median (range) and proportions for continuous and categorical data, respectively. The effect of each variable-specified in Table 1-on 90- and 180-day shunt failure was evaluated using generalized estimating equations to account for correlated observations over time. Bivariate analyses were first performed to evaluate individual effects of each independent variable on shunt failure at 90 days and at 180 days. Any independent variable with $\mathrm{p}<0.2$ in the bivariate analyses was included in the initial multivariate analyses to assess effects after adjustment for shunt failure at 90 days and at 180 days. Afterward, a final model was chosen for each outcome by using a backward model selection approach, which is an iterative process that ended when all remaining variables were statistically significant at our prespecified significance level of 0.05 . Unadjusted and adjusted odds ratio estimates, along with corresponding $95 \%$ confidence intervals, were provided based on the bivariate and multivariate analyses, respectively. All analyses were performed using SAS version 9.3 (SAS Institute, Inc.).

\section{Results}

There were 466 patients included in our study accounting for 739 unique operations, for an average of 1.59 procedures per patient. There were more males (53.9\%), with the median age for the cohort at time of first shunt surgery being 5 years (range $0-36$ years); the vast majority (440, or $94.4 \%$ ) were 18 years or younger. Descriptive statistics for variables that were collected on the initial procedure performed for each eligible patient are presented in Table 2 for 90- and 180-day failure from the first index procedure and overall. Among the 739 index shunt operations there 
TABLE 2. Descriptive statistics for each variable for 466 patients at the time of the first index shunt surgery and for 90 - and 180 -day shunt failures from that initial index surgery

\begin{tabular}{|c|c|c|c|}
\hline Variable & 90-Day Failure, No. (\%) & 180-Day Failure, No. (\%) & Overall No. (\%) \\
\hline \multicolumn{4}{|l|}{ Age categories } \\
\hline Birth-12 mos & $26(28.26)$ & $40(33.61)$ & $143(30.69)$ \\
\hline$>12$ mos- 5 yrs & $19(20.65)$ & $24(20.17)$ & $89(19.10)$ \\
\hline$>5-10$ yrs & $24(26.09)$ & $28(23.53)$ & $96(20.6)$ \\
\hline$>10 \mathrm{yrs}$ & $23(25)$ & $27(22.69)$ & $138(29.61)$ \\
\hline \multicolumn{4}{|l|}{ Sex } \\
\hline Female & $40(43.48)$ & $54(45.38)$ & $215(46.14)$ \\
\hline Male & $52(56.52)$ & $65(54.62)$ & $251(53.86)$ \\
\hline \multicolumn{4}{|l|}{ Race } \\
\hline African American & $36(39.13)$ & $51(42.86)$ & $207(44.42)$ \\
\hline Other & $5(5.43)$ & $7(5.88)$ & $35(7.51)$ \\
\hline Caucasian & $51(55.43)$ & $61(51.26)$ & $224(48.07)$ \\
\hline \multicolumn{4}{|l|}{ Payor source } \\
\hline Private & $33(35.87)$ & $43(36.13)$ & $165(35.41)$ \\
\hline Government & $59(64.13)$ & $76(63.87)$ & $301(64.59)$ \\
\hline \multicolumn{4}{|l|}{ Etiology of hydrocephalus } \\
\hline Congenital & $19(20.65)$ & $23(19.33)$ & $82(17.6)$ \\
\hline Dysraphism & $6(6.52)$ & $11(9.24)$ & $60(12.88)$ \\
\hline Other & $14(15.22)$ & $18(15.13)$ & $72(15.45)$ \\
\hline Neoplastic & $27(29.35)$ & $31(26.05)$ & $118(25.32)$ \\
\hline PHHP & $26(28.26)$ & $36(30.25)$ & $134(28.76)$ \\
\hline \multicolumn{4}{|l|}{ Shunt type } \\
\hline Ventriculoatrial + ventriculopleural & $0(0)$ & $2(1.68)$ & $14(3)$ \\
\hline Ventriculoperitoneal & $92(100)$ & $117(98.32)$ & $452(97)$ \\
\hline \multicolumn{4}{|l|}{ Proximal catheter location } \\
\hline Both & $3(3.26)$ & $3(2.52)$ & $10(2.15)$ \\
\hline Frontal & $36(39.13)$ & $46(38.66)$ & $167(35.84)$ \\
\hline Occipital & $53(57.61)$ & $70(58.82)$ & $289(62.02)$ \\
\hline \multicolumn{4}{|l|}{ Slit ventricles at time of index surgery } \\
\hline Yes & $6(6.52)$ & $9(7.56)$ & $19(4.08)$ \\
\hline No & $86(93.48)$ & $110(92.44)$ & 447 (95.92) \\
\hline \multicolumn{4}{|l|}{ History of shunt or ventricular infection } \\
\hline Yes & $7(7.61)$ & $7(5.88)$ & $27(5.79)$ \\
\hline No & $85(92.39)$ & $112(94.12)$ & 439 (94.21) \\
\hline \multicolumn{4}{|c|}{ Index surgery due to recently treated shunt infection } \\
\hline Yes & $4(4.35)$ & $5(4.2)$ & $12(2.58)$ \\
\hline No & $88(95.65)$ & $114(95.8)$ & $454(97.42)$ \\
\hline \multicolumn{4}{|c|}{ Index surgery performed after elective intradural surgery } \\
\hline Yes & $14(15.22)$ & $15(12.61)$ & $58(12.45)$ \\
\hline No & $78(84.78)$ & $104(87.39)$ & $408(87.55)$ \\
\hline \multicolumn{4}{|l|}{ Type of index surgery } \\
\hline Complete revision & $8(8.7)$ & $8(6.72)$ & $28(6.01)$ \\
\hline Distal revision & $13(14.13)$ & $16(13.45)$ & $95(20.39)$ \\
\hline Other & $2(2.17)$ & $3(2.52)$ & $10(2.15)$ \\
\hline Proximal revision & $28(30.43)$ & $35(29.41)$ & $114(24.46)$ \\
\hline New placement & $41(44.57)$ & $47(47.9)$ & $219(47)$ \\
\hline
\end{tabular}


TABLE 2. Descriptive statistics for each variable for 466 patients at the time of the first index shunt surgery and for 90 - and 180 -day shunt failures from that initial index surgery (continued)

\begin{tabular}{|c|c|c|c|}
\hline Variable & 90-Day Failure, No. (\%) & 180-Day Failure, No. (\%) & Overall No. (\%) \\
\hline \multicolumn{4}{|c|}{ Intraventricular hemorrhage at index surgery } \\
\hline Yes & $7(7.61)$ & $8(6.72)$ & $18(3.86)$ \\
\hline No & $85(92.39)$ & $111(93.28)$ & $448(96.14)$ \\
\hline \multicolumn{4}{|l|}{ Image guidance } \\
\hline Stereotactic & $10(10.87)$ & $14(11.76)$ & $44(9.44)$ \\
\hline Ultrasound & $1(1.09)$ & $1(0.84)$ & $5(1.07)$ \\
\hline No & $81(88.04)$ & $104(87.39)$ & $417(89.48)$ \\
\hline \multicolumn{4}{|l|}{ Primary surgeon } \\
\hline 1 & $28(30.43)$ & $37(31.09)$ & $131(28.11)$ \\
\hline 2 & $14(15.22)$ & $15(12.61)$ & $91(19.53)$ \\
\hline 3 & $21(22.83)$ & $31(26.05)$ & $127(27.25)$ \\
\hline 4 & $2(2.17)$ & $2(1.68)$ & $12(2.58)$ \\
\hline 5 & $27(29.35)$ & $34(28.57)$ & $105(22.53)$ \\
\hline Age in $\mathrm{yrs}^{*}$ & $5.1(0-25.88)$ & $4.04(0-25.88)$ & $5.03(0-35.65)$ \\
\hline Operative time (min) ${ }^{*}$ & $46.5(16-277)$ & $45(16-277)$ & $45(13-277)$ \\
\hline Functional proximal catheters* & $1(0-3)$ & $1(0-3)$ & $1(0-3)$ \\
\hline Prior ventricular shunt surgeries* & $1(0-28)$ & $1(0-28)$ & $1(0-18)$ \\
\hline
\end{tabular}

* Data are presented as the median (range) for the last 4 variables.

were a total of 221 shunt failures, yielding a shunt failure rate of $24.1 \%$ within 90 days and $29.9 \%$ within 180 days. Accordingly, of the 561 procedures that did not require revision within 90 days, $92.3 \%$ did not require revision within 180 days.

\section{Shunt Revision at 90 Days}

Bivariate results are presented in Table 3 . Variables with $\mathrm{p}<0.2$ included shunt type $(\mathrm{p}=0.08)$, number of functional proximal catheters $(\mathrm{p}=0.18)$, use of image guidance $(\mathrm{p}=0.18)$, and operative time $(\mathrm{p}=0.14)$. These variables were further examined in the multivariate model to assess the significance of each factor and its effect on 90-day shunt failure, while adjusting for the other variables in the model (Table 4). Afterward, the backward model selection procedure was used to retain only those variables with $\mathrm{p}<0.05$, which ultimately resulted in no such variables. Although not statistically significant, it is worth noting that a ventriculoperitoneal shunt is 3.8 (or $1 / 0.2656$ ) times more likely to fail in 90 days than either a ventriculoatrial or ventriculopleural shunt.

\section{Shunt Revision at 180 Days}

Bivariate results are presented in Table 5. The following variables resulted in $p<0.2$ : proximal catheter location $(\mathrm{p}=0.06)$, number of functional proximal catheters $(\mathrm{p}$ $=0.07)$, slit ventricles at the time of the index surgery $(\mathrm{p}$ $=0.14)$, number of prior shunt operations $(\mathrm{p}=0.12)$, index surgery due to treated shunt infection $(\mathrm{p}=0.08)$, and type of index surgery $(\mathrm{p}=0.16)$. Multivariate analysis results are shown in Table 6. Only 1 variable was significant (index surgery due to recently treated shunt infection, $\mathrm{p}=$ 0.04 ), but this did not retain statistical significance with the backward model selection procedure.

\section{Discussion \\ Our Findings}

Our database contains a multitude of variables collected for nearly every ventricular shunt surgery performed at our institution during a 4-year period. Bivariate testing revealed some variables to be associated with both 90and 180-day failure rates. The only variable found to be significant on multivariate testing was index surgery due to recent shunt infection for the 180-day shunt failure outcome; however, no variables were independently predictive of shunt failure at 90 days, and the lone variable that was significant on multivariate testing for 180-day failure was not validated with the backward model selection procedure. In other words, we found no variable-demographic, clinical, or procedural-to be predictive of shunt malfunction within 90 or 180 days after an index surgery.

As previously mentioned, prior research has identified several variables that appear to influence shunt survival, including a patient's age, number of prior revisions, and etiology of hydrocephalus; ;,6,10,19,21,25,34 however, the literature includes conflicting results on this topic, and several studies may indicate that shunt survival is impacted by one or more of these variables, while others do not. ${ }^{4,6,10,19,21,25,34}$ Our study, unfortunately, has added to this confusing picture. Multiple pediatric studies have reported younger age as a variable associated with increased risk of shunt failure, $4,6,8,25,34$ however, whether age is kept as a continuous variable or categorized varies from study to study. For example, McGirt et al. ${ }^{21} \mathrm{kept}$ it as a continuous variable as well as making "gestation age $<40$ weeks" a separate variable, whereas Ferguson et al. ${ }^{8}$ categorized it as 0-2 years, $2.1-17$ years, and $>17$ years, and Tuli et al. ${ }^{34}$ categorized it as $<40$ weeks gestation, 40 weeks-1 year, and 
TABLE 3. Bivariate results for 90-day shunt failure

\begin{tabular}{|c|c|c|c|}
\hline Variable & OR & $95 \% \mathrm{Cl}$ & $p$ Value \\
\hline Age (yrs) & 1.0107 & $(0.9769-1.0457)$ & 0.5403 \\
\hline Age categories & & & 0.8215 \\
\hline$>12$ mos -5 yrs & 1.1218 & $(0.6284-2.0023)$ & 0.6975 \\
\hline$>5-10$ yrs & 1.3187 & $(0.7285-2.3871)$ & 0.3609 \\
\hline$>10 \mathrm{yrs}$ & 1.2243 & $(0.6757-2.2184)$ & 0.5046 \\
\hline Birth-12 mos & Reference & & \\
\hline Sex (female vs male) & 0.8611 & $(0.5680-1.3055)$ & 0.4813 \\
\hline Race & & & 0.4275 \\
\hline African American & 0.7555 & $(0.4906-1.1636)$ & 0.2033 \\
\hline Other & 0.7911 & $(0.3593-1.7419)$ & 0.5606 \\
\hline Caucasian & Reference & & \\
\hline Payor source (private vs government) & 0.8591 & $(0.5619-1.3134)$ & 0.4832 \\
\hline Etiology of hydrocephalus & & & 0.2261 \\
\hline Congenital & 1.1575 & $(0.6252-2.1430)$ & 0.6417 \\
\hline Dysraphism & 0.4250 & $(0.1861-0.9702)$ & 0.0422 \\
\hline Other & 1.1663 & $(0.6074-2.2395)$ & 0.6440 \\
\hline Neoplastic & 0.9846 & $(0.5889-1.6460)$ & 0.9528 \\
\hline PHHP & Reference & & \\
\hline Shunt type (ventriculoatrial + ventriculopleural vs ventriculoperitoneal) & 0.2591 & $(0.0565-1.1886)$ & 0.0823 \\
\hline Proximal catheter location & & & 0.2135 \\
\hline Both & 2.4083 & $(0.5042-11.5035)$ & 0.2706 \\
\hline Frontal & 1.3883 & $(0.9066-2.1261)$ & 0.1313 \\
\hline Occipital & Reference & & \\
\hline Functional proximal catheters & 1.4131 & $(0.8490-2.3522)$ & 0.1835 \\
\hline Slit ventricles at time of index surgery (yes) & 1.7516 & $(0.6949-4.4151)$ & 0.2347 \\
\hline Prior ventricular shunt surgery & 0.9985 & $(0.9202-1.0836)$ & 0.9720 \\
\hline History of shunt or ventricular infection (yes) & 1.6060 & $(0.7584-3.4008)$ & 0.2159 \\
\hline Index surgery due to recently treated shunt infection (yes) & 1.3880 & $(0.4966-3.8793)$ & 0.5318 \\
\hline Index surgery performed after elective intradural surgery (yes) & 1.4447 & $(0.7611-2.7423)$ & 0.2605 \\
\hline Type of index surgery & & & 0.3358 \\
\hline Complete revision & 1.4256 & $(0.6507-3.1233)$ & 0.3755 \\
\hline Distal revision & 0.6292 & $(0.3052-1.2974)$ & 0.2096 \\
\hline Other & 1.5677 & $(0.5214-4.7136)$ & 0.4235 \\
\hline Proximal revision & 1.1184 & $(0.6564-1.9056)$ & 0.6806 \\
\hline New placement & Reference & & \\
\hline Intraventricular hemorrhage at index surgery (yes) & 1.0948 & $(0.3221-3.7213)$ & 0.8846 \\
\hline Image guidance & & & 0.1819 \\
\hline Stereotactic & 1.7713 & $(0.8789-3.5695)$ & 0.1098 \\
\hline Ultrasound & 1.5532 & $(0.6393-3.7734)$ & 0.3310 \\
\hline No & Reference & & \\
\hline Operative time & 1.0037 & $(0.9988-1.0087)$ & 0.1382 \\
\hline Primary surgeon & & & 0.4261 \\
\hline 1 & 0.7384 & $(0.4086-1.3342)$ & 0.3150 \\
\hline 2 & 0.5979 & $(0.2815-1.2700)$ & 0.1809 \\
\hline 3 & 0.5145 & $(0.2554-1.0365)$ & 0.0629 \\
\hline 4 & 0.6314 & $(0.1757-2.2694)$ & 0.4811 \\
\hline 5 & Reference & & \\
\hline
\end{tabular}

* The $p$ values in bold refer to the $<0.2$ level of significance in the 90 -day bivariate analysis as described in the Results section. For variables that have multiple entries it only refers to first $p$ value, which is the global measure of significance for that variable. 
TABLE 4. Multivariate results for 90 -day shunt failure

\begin{tabular}{lccc}
\hline \multicolumn{1}{c}{ Variable } & $\mathrm{OR}$ & $95 \% \mathrm{Cl}$ & $\mathrm{p} \mathrm{Value}$ \\
\hline Shunt type (ventriculoatrial + ventriculopleural vs ventriculoperitoneal) & 0.2656 & $(0.0576-1.2249)$ & 0.0892 \\
\hline Functional proximal catheters & 1.3559 & $(0.8175-2.2487)$ & 0.2382 \\
\hline Image guidance & & & 0.4251 \\
\hline Stereotactic & 1.4938 & $(0.7658-2.9139)$ & 0.2391 \\
\hline Ultrasound & 1.4059 & $(0.5355-3.6910)$ & 0.4890 \\
\hline No & Reference & & \\
\hline Operative time & 1.0029 & $(0.9978-1.0080)$ & 0.2717 \\
\hline
\end{tabular}

$>1$ year. Even the 30-day SMR uses age as part of its risk stratification, defined as 0-30 days, 31-365 days, and $>1$ year. Our data do not support age as an independent risk factor for shunt failure, either as a categorical or continuous variable.

A number of studies have identified etiology of hydrocephalus as a predictor of shunt failure., ${ }^{4,634}$ Berry et al. previously identified spina bifida as a predictor of multiple shunt failures. ${ }^{4}$ We found that the diagnosis of spinal dysraphism compared with posthemorrhagic hydrocephalus of prematurity (PHHP) was protective (OR 0.43 ) in the bivariate analysis for 90-day failure, but the category as a whole (i.e., etiology of hydrocephalus) was not significant. We also investigated the impact of who performed the shunt surgery, which is an important and often overlooked potential factor when evaluating a surgical procedure. It too did not affect shunt failure at our institution. Simon and colleagues reported an overall 6-month reinfection rate of $14.8 \%$ (100 of 675) in children treated for an initial shunt infection, as well as an association between revision surgery and risk of shunt infection; ${ }^{30,31}$ however, in our study a recently treated shunt infection was found to be significant on multivariate testing for the 180-day outcome (OR 2.25, p = 0.0419), but not after subjecting it to the backward model selection procedure.

\section{Implications of the Findings}

Although this is a negative study, we believe that our findings have important ramifications. When the word "quality" is paired with the term "measure," it implies that one of the primary functions of the measure is to compare surgeons or hospitals to each other. It is our opinion that a quality measure is one that must satisfy 3 core criteria, or the "3 Ms": Make sense, be Measureable, and be Modifiable. First, the metric should make sense to providers, patients, and their families. The measure, therefore, will typically be either a maximized positive outcome or a minimized adverse event. Second, the metric must be easily measured with minimal to no ambiguity or subjectivity. Third, and most importantly, the metric or outcome of interest must be modifiable by one or more interventions or a process that has theoretical or proven impact on the occurrence of the metric. Specific to pediatric neurosurgery, such an intervention would be under the direction or control of the surgeon during the pre-, intra-, or postoperative period. However, an institution's or even an individual surgeon's raw or global shunt revision rate as a quality measure falls short because there are no universally accepted risk factors, and those that have been postulated are all nonmodifiable. Unless there are at least some adjustable factors, risk stratification based on nonadjustable factors is likewise inappropriate. In their 2000 paper, Tuli et al. ${ }^{34}$ summarized the dilemma:

The results, however, are somewhat dismaying in that none of the easily remedied factors, such as shunt valve design, shunt implantation site, length of surgery, and use of antibiotic agents, appeared to be significant. Instead, unchangeable patient characteristics such as age as well as cause of hydrocephalus were found to be significant. This is extremely important information, however, because it may prevent investigators from pursuing treatment strategies that are unlikely to have any effect.

It would be inconceivable and unethical for any hospital or surgeon to preferentially treat children with hydrocephalus based on such nonmodifiable features as age or the cause of their hydrocephalus, in an effort to improve the practitioner's or institution's outcomes and rankings.

Currently, the only quality metric for pediatric shunt surgery that satisfies our 3 criteria is infection rate. The literature is replete with risk factors and interventions that have impacted the infection rate, such as doublegloving and the use of antibiotic-impregnated shunt catheters. ${ }^{12,17,18,27,35}$ There is ample evidence from the literature that the creation and implementation of shunt surgery checklists-which incorporate a number of infection-prevention strategies-work. For example, the checklist put forth by the Hydrocephalus Clinical Research Network (HCRN) has specified steps such as the use of appropriate hand-washing techniques, double-gloving, and perioperative antibiotics, which have resulted in a relative risk reduction of $36 \% .^{16}$

But we as surgeons know that there are certain shunt reoperations that could have been prevented. Surgeons control 2 aspects of shunt surgery that are potentially modifiable: technique and technology. Surgical technique is focused on expeditiously placing the proximal and distal ends of the shunt in their respective optimal locations, while minimizing the risk of infection. Our study found no association between duration of surgery and shunt failure. There has been much interest in the use of intraoperative imaging modalities, namely ultrasound and electromagnetic frameless stereotaxy, to help accurately position the proximal catheter. Levitt et al. demonstrated that the use of electromagnetic image guidance could improve the ac- 
TABLE 5. Bivariate results for 180 -day shunt failure

\begin{tabular}{|c|c|c|c|}
\hline Variable & OR & $95 \% \mathrm{Cl}$ & $p$ Value* \\
\hline Age (yrs) & 0.9956 & $(0.9627-1.0297)$ & 0.7989 \\
\hline Age categories & & & 0.9861 \\
\hline$>12$ mos -5 yrs & 1.0277 & $(0.6285-1.6804)$ & 0.9134 \\
\hline$>5-10$ yrs & 1.0686 & $(0.6522-1.7509)$ & 0.7922 \\
\hline$>10 \mathrm{yrs}$ & 0.9636 & $(0.5564-1.6689)$ & 0.8947 \\
\hline Birth-12 mos & Reference & & \\
\hline Sex (female vs male) & 0.9622 & $(0.6600-1.4028)$ & 0.8412 \\
\hline Race & & & 0.7379 \\
\hline African American & 0.8796 & $(0.5949-1.3006)$ & 0.5204 \\
\hline Other & 0.8066 & $(0.3921-1.6592)$ & 0.5591 \\
\hline Caucasian & Reference & & \\
\hline Payor source (private vs government) & 0.8766 & $(0.6022-1.2760)$ & 0.4917 \\
\hline Etiology of hydrocephalus & & & 0.2573 \\
\hline Congenital & 1.0142 & $(0.5576-1.8448)$ & 0.9631 \\
\hline Dysraphism & 0.5280 & $(0.2744-1.0160)$ & 0.0558 \\
\hline Other & 1.1414 & $(0.6561-1.9855)$ & 0.6397 \\
\hline Neoplastic & 0.7999 & $(0.5056-1.2653)$ & 0.3399 \\
\hline PHHP & Reference & & \\
\hline Shunt type (ventriculoatrial + ventriculopleural vs ventriculoperitoneal) & 0.5563 & $(0.1810-1.7095)$ & 0.3059 \\
\hline Proximal catheter location & & & 0.0585 \\
\hline Both & 2.5200 & $(0.8176-7.7668)$ & 0.1075 \\
\hline Frontal & 1.3993 & $(0.9836-1.9907)$ & 0.0617 \\
\hline Occipital & Reference & & \\
\hline Functional proximal catheters & 1.4938 & $(0.9673-2.3068)$ & 0.0703 \\
\hline Slit ventricles at time of index surgery (yes) & 1.5774 & $(0.8660-2.8733)$ & 0.1363 \\
\hline Prior ventricular shunt surgery & 1.0470 & $(0.9879-1.1096)$ & 0.1211 \\
\hline History of shunt or ventricular infection (yes) & 1.0414 & $(0.4930-2.1998)$ & 0.9153 \\
\hline Index surgery due to recently treated shunt infection (yes) & 1.9947 & $(0.9096-4.3740)$ & 0.0848 \\
\hline Index surgery performed after elective intradural surgery (yes) & 1.1938 & $(0.6377-2.2346)$ & 0.5798 \\
\hline Type of index surgery & & & 0.1588 \\
\hline Complete revision & 1.3138 & $(0.6903-2.5004)$ & 0.4059 \\
\hline Distal revision & 0.6085 & $(0.3607-1.0267)$ & 0.0627 \\
\hline Other & 1.0309 & $(0.3704-2.8692)$ & 0.9535 \\
\hline Proximal revision & 1.0877 & $(0.6806-1.7383)$ & 0.7252 \\
\hline New placement & Reference & & \\
\hline Intraventricular hemorrhage at index surgery (yes) & 1.2296 & $(0.5209-2.9025)$ & 0.6371 \\
\hline Image guidance & & & 0.2852 \\
\hline Stereotactic & 1.4910 & $(0.8643-2.5721)$ & 0.1511 \\
\hline Ultrasound & 1.3692 & $(0.5306-3.5328)$ & 0.5159 \\
\hline No & Reference & & \\
\hline Operative time & 1.0026 & $(0.9981-1.0071)$ & 0.2574 \\
\hline Primary surgeon & & & 0.4664 \\
\hline 1 & 0.8224 & $(0.5304-1.2751)$ & 0.3822 \\
\hline 2 & 0.5960 & $(0.3334-1.0655)$ & 0.0808 \\
\hline 3 & 0.7200 & $(0.4411-1.1751)$ & 0.1887 \\
\hline 4 & 0.7683 & $(0.2815-2.0973)$ & 0.6070 \\
\hline 5 & Reference & & \\
\hline
\end{tabular}

* The $p$ values in bold refer to the $<0.2$ level of significance in the 180-day bivariate analysis as described in the Results section. For variables that have multiple entries it only refers to first $p$ value, which is the global measure of significance for that variable. 
TABLE 6. Multivariate results for 180-day shunt failure

\begin{tabular}{lccc}
\hline \multicolumn{1}{c}{ Variable } & OR & $95 \% \mathrm{Cl}$ & $\mathrm{p} \mathrm{Value}$ \\
\hline Proximal catheter location & & & 0.1260 \\
\hline Both & 1.7610 & $(0.7401-4.1903)$ & 0.2007 \\
\hline Frontal & 1.3543 & $(0.9624-1.9059)$ & 0.0818 \\
\hline Occipital & Reference & & 0.0954 \\
\hline Functional proximal catheters & 1.3661 & $(0.9468-1.9710)$ & 0.2023 \\
\hline Slit ventricles at time of index surgery (yes) & 1.4533 & $(0.8181-2.5817)$ & 0.1237 \\
\hline Prior ventricular shunt surgery & 1.0421 & $(0.9888-1.0983)$ & $0.0419^{*}$ \\
\hline Index surgery due to recently treated shunt infection (yes) & 2.2480 & $(1.0301-4.9061)$ & 0.0811 \\
\hline Type of index surgery & & & 0.9687 \\
\hline Complete revision & 0.9869 & $(0.5094-1.9120)$ & 0.0223 \\
\hline Distal revision & 0.5372 & $(0.3152-0.9155)$ & 0.4349 \\
\hline Other & 0.6841 & $(0.2638-1.7739)$ & 0.9783 \\
\hline Proximal revision & 0.9938 & $(0.6360-1.5531)$ & \\
\hline New placement & Reference & & \\
\hline * Statistically significant. & & & \\
\hline
\end{tabular}

curacy of catheter placement, but had no effect on shunt system survival. ${ }^{20}$ On the other hand, Janson et al. showed an improvement in shunt survivability with the use of ultrasound image guidance for catheter placement. ${ }^{13}$ A literature review conducted as part of the recently published Pediatric Hydrocephalus Guidelines concluded that there is as yet no proven benefit. ${ }^{9}$ We too did not find a shunt success benefit with the use of ultrasound or electromagnetic navigation, but this was because the number of cases in which this technology was used was small (i.e., underpowered). Another surgical technique that may improve shunt survival is laparoscopic placement of the distal catheter. A recent randomized trial in adult patients suggested that laparoscopic placement of the distal catheter led to less distal failures compared with minilaparotomy, although the overall shunt failure rate was no different between the 2 groups. $^{28}$

We are currently attempting to quantify and define what we term the Preventable Shunt Revision Rate (PSRR) as a potential shunt surgery measure. Revision shunt surgery performed because of a malpositioned proximal catheter (e.g., a hole-bearing region of the catheter completely within parenchyma) or distal catheter (e.g., preperitoneal placement), or shunt components that were not properly assembled or secured are examples of errors in surgical technique that could be prevented. What cannot be easily quantified is a surgeon's judgment-i.e., performing the right operation on the right patient at the right time. Errors in judgment are other preventable reasons why shunts fail, but they are very difficult-if not impossible - to evaluate objectively.

\section{Strengths and Limitations}

One strength of our study is that it comes from a single center in which the data were collected by a small group of knowledgeable and trained researchers, with multiple data checks to ensure integrity and quality while minimizing inconsistencies or missing information. Nevertheless, there are inherent limitations with retrospective data collection. Patient and procedure data were accrued over a number of consecutive years with a reasonable number of patients and procedures. There is currently a trend within the neurosurgical literature to use hospital administrative databases, which can contain large numbers of patients from multiple institutions, but unless the database has been created by neurosurgeons for neurosurgeons with the necessary granularity, it is of limited value. The strengths of these databases are that they contain thousands of patients, which allow researchers to detect small differences, but such small differences may be of questionable clinical significance. Research from neurosurgery-specific databases, such as those created by the HCRN or the National Neurosurgery Quality and Outcomes Database (N²QOD), will produce results that are more accurate and relevant to neurosurgeons. A substantially larger database than ours and one that is ideally prospectively maintained is most likely needed to investigate all current and future variables with adequate power and data integrity. To this end, we are continuing to add to our database and plan to repeat our analysis in several years.

We did not examine the time of year that shunt surgeries were performed to explore the so-called July effect. ${ }^{15,32}$ We did not believe that this was a necessary area to investigate, because at our institution all shunt operations are done with the direct supervision and participation of the attending surgeon. We also did not take into account the type of valve used because we rarely implant programmable or flow-regulated valves. Finally, we plan to perform a more detailed analysis of whether the time interval between failures has any pattern or predictive ability in those patients with multiple shunt failures. ${ }^{19,34}$

\section{Conclusions}

Shunt surgery will always remain a large part of the pediatric neurosurgeon's practice. Revision rates will also remain high because all of the current potential predic- 
tors of shunt failure are nonmodifiable. Our study demonstrates that for our institution there were no predictors of shunt failure at 90 and 180 days. Based on the results of our study and others, there is ample evidence supporting the assertion that the global shunt revision rate should be studied further prior to concluding that it should be used as a quality metric. Additional research is needed to clarify what percentage of shunt failures are potentially preventable and then to determine what steps, if any, can be taken to decrease the shunt failure rate.

\section{Acknowledgment}

We thank Andrew J. Gienapp (Department of Medical Education, Methodist University Hospital, Memphis, Tennessee, and Department of Neurosurgery, University of Tennessee Health Science Center, Memphis, Tennessee) for technical and copy editing, preparation of the manuscript for publishing, and publication assistance with this manuscript.

\section{References}

1. Baird LC, Mazzola CA, Auguste KI, Klimo P Jr, Flannery AM: Pediatric hydrocephalus: systematic literature review and evidence-based guidelines. Part 5: Effect of valve type on cerebrospinal fluid shunt efficacy. J Neurosurg Pediatr 14 (Suppl 1):35-43, 2014

2. Barton SE, Campbell JW, Piatt JH Jr: Quality measures for the management of hydrocephalus: concepts, simulations, and preliminary field-testing. J Neurosurg Pediatr 11:392-397, 2013

3. Beez T, Sarikaya-Seiwert S, Bellstädt L, Mühmer M, Steiger HJ: Role of ventriculoperitoneal shunt valve design in the treatment of pediatric hydrocephalus--a single center study of valve performance in the clinical setting. Childs Nerv Syst 30:293-297, 2014

4. Berry JG, Hall MA, Sharma V, Goumnerova L, Slonim AD, Shah SS: A multi-institutional, 5-year analysis of initial and multiple ventricular shunt revisions in children. Neurosurgery 62:445-454, 2008

5. Berry JG, Toomey SL, Zaslavsky AM, Jha AK, Nakamura MM, Klein DJ, et al: Pediatric readmission prevalence and variability across hospitals. JAMA 309:372-380, 2013

6. Di Rocco C, Marchese E, Velardi F: A survey of the first complication of newly implanted CSF shunt devices for the treatment of nontumoral hydrocephalus. Cooperative survey of the 1991-1992 Education Committee of the ISPN. Childs Nerv Syst 10:321-327, 1994

7. Federman AD, Keyhani S: Physicians' participation in the Physicians' Quality Reporting Initiative and their perceptions of its impact on quality of care. Health Policy 102:229-234, 2011

8. Ferguson SD, Michael N, Frim DM: Observations regarding failure of cerebrospinal fluid shunts early after implantation. Neurosurg Focus 22(4):E7, 2007

9. Flannery AM, Duhaime AC, Tamber MS, Kemp J: Pediatric hydrocephalus: systematic literature review and evidencebased guidelines. Part 3: Endoscopic computer-assisted electromagnetic navigation and ultrasonography as technical adjuvants for shunt placement. J Neurosurg Pediatr 14 (Suppl 1):24-29, 2014

10. Griebel R, Khan M, Tan L: CSF shunt complications: an analysis of contributory factors. Childs Nerv Syst 1:77-80, 1985

11. Hatlen TJ, Shurtleff DB, Loeser JD, Ojemann JG, Avellino AM, Ellenbogen RG: Nonprogrammable and programmable cerebrospinal fluid shunt valves: a 5-year study. J Neurosurg Pediatr 9:462-467, 2012
12. James G, Hartley JC, Morgan RD, Ternier J: Effect of introduction of antibiotic-impregnated shunt catheters on cerebrospinal fluid shunt infection in children: a large singlecenter retrospective study. J Neurosurg Pediatr 13:101-106, 2014

13. Janson CG, Romanova LG, Rudser KD, Haines SJ: Improvement in clinical outcomes following optimal targeting of brain ventricular catheters with intraoperative imaging. J Neurosurg 120:684-696, 2014

14. Kestle JR: Administrative database research. J Neurosurg 122:441-442, 2015

15. Kestle JR, Cochrane DD, Drake JM: Shunt insertion in the summer: is it safe? J Neurosurg 105 (3 Suppl):165-168, 2006

16. Kestle JR, Riva-Cambrin J, Wellons JC III, Kulkarni AV, Whitehead WE, Walker ML, et al: A standardized protocol to reduce cerebrospinal fluid shunt infection: the Hydrocephalus Clinical Research Network Quality Improvement Initiative. J Neurosurg Pediatr 8:22-29, 2011

17. Klimo P Jr, Thompson CJ, Baird LC, Flannery AM: Pediatric hydrocephalus: systematic literature review and evidencebased guidelines. Part 7: Antibiotic-impregnated shunt systems versus conventional shunts in children: a systematic review and meta-analysis. J Neurosurg Pediatr 14 (Suppl 1):53-59, 2014

18. Klimo P Jr, Thompson CJ, Ragel BT, Boop FA: Antibioticimpregnated shunt systems versus standard shunt systems: a meta- and cost-savings analysis. J Neurosurg Pediatr 8:600-612, 2011

19. Lazareff JA, Peacock W, Holly L, Ver Halen J, Wong A, Olmstead C: Multiple shunt failures: an analysis of relevant factors. Childs Nerv Syst 14:271-275, 1998

20. Levitt MR, O’Neill BR, Ishak GE, Khanna PC, Temkin NR, Ellenbogen RG, et al: Image-guided cerebrospinal fluid shunting in children: catheter accuracy and shunt survival. J Neurosurg Pediatr 10:112-117, 2012

21. McGirt MJ, Leveque JC, Wellons JC III, Villavicencio AT, Hopkins JS, Fuchs HE, et al: Cerebrospinal fluid shunt survival and etiology of failures: a seven-year institutional experience. Pediatr Neurosurg 36:248-255, 2002

22. McGirt MJ, Parker SL, Asher AL, Norvell D, Sherry N, Devin CJ: Role of prospective registries in defining the value and effectiveness of spine care. Spine (Phila Pa 1976) 39 (22 Suppl 1):S117-S128, 2014

23. Patwardhan RV, Nanda A: Implanted ventricular shunts in the United States: the billion-dollar-a-year cost of hydrocephalus treatment. Neurosurgery 56:139-145, 2005

24. Piatt JH Jr: Thirty-day outcomes of cerebrospinal fluid shunt surgery: data from the National Surgical Quality Improvement Program-Pediatrics. J Neurosurg Pediatr 14:179-183, 2014

25. Piatt JH Jr, Carlson CV: A search for determinants of cerebrospinal fluid shunt survival: retrospective analysis of a 14-year institutional experience. Pediatr Neurosurg 19:233242, 1993

26. Piatt JH Jr, Freibott CE: Quality measurement in the shunt treatment of hydrocephalus: analysis and risk adjustment of the Revision Quotient. J Neurosurg Pediatr 14:48-54, 2014

27. Rehman AU, Rehman TU, Bashir HH, Gupta V: A simple method to reduce infection of ventriculoperitoneal shunts. J Neurosurg Pediatr 5:569-572, 2010

28. Schucht P, Banz V, Trochsler M, Iff S, Krahenbuhl AK, Reinert M, et al: Laparoscopically assisted ventriculoperitoneal shunt placement: a prospective randomized controlled trial. J Neurosurg 122:1058-1067, 2015

29. Shah SS, Hall M, Slonim AD, Hornig GW, Berry JG, Sharma V: A multicenter study of factors influencing cerebrospinal fluid shunt survival in infants and children. Neurosurgery 62:1095-1103, 2008 
30. Simon TD, Hall M, Dean JM, Kestle JR, Riva-Cambrin J: Reinfection following initial cerebrospinal fluid shunt infection. J Neurosurg Pediatr 6:277-285, 2010

31. Simon TD, Whitlock KB, Riva-Cambrin J, Kestle JR, Rosenfeld M, Dean JM, et al: Revision surgeries are associated with significant increased risk of subsequent cerebrospinal fluid shunt infection. Pediatr Infect Dis J 31:551-556, 2012

32. Smith ER, Butler WE, Barker FG II: Is there a "July phenomenon" in pediatric neurosurgery at teaching hospitals? J Neurosurg 105 (3 Suppl):169-176, 2006

33. Stone SS, Warf BC: Combined endoscopic third ventriculostomy and choroid plexus cauterization as primary treatment for infant hydrocephalus: a prospective North American series. J Neurosurg Pediatr 14:439-446, 2014

34. Tuli S, Drake J, Lawless J, Wigg M, Lamberti-Pasculli M: Risk factors for repeated cerebrospinal shunt failures in pediatric patients with hydrocephalus. J Neurosurg 92:31-38, 2000

35. Tulipan N, Cleves MA: Effect of an intraoperative doublegloving strategy on the incidence of cerebrospinal fluid shunt infection. J Neurosurg 104 (1 Suppl):5-8, 2006

36. Wachter RM, Foster NE, Dudley RA: Medicare's decision to withhold payment for hospital errors: the devil is in the det. Jt Comm J Qual Patient Saf 34:116-123, 2008

\section{Disclosure}

The authors report no conflict of interest concerning the materials or methods used in this study or the findings specified in this paper.

\section{Author Contributions}

Conception and design: Klimo. Acquisition of data: Khan, Lepard, McAbee. Analysis and interpretation of data: Klimo, Rossi, Khan, Jones. Drafting the article: Klimo, Rossi, Khan. Critically revising the article: Klimo, Rossi, Khan, Jones. Reviewed submitted version of manuscript: Klimo, Rossi, Jones. Approved the final version of the manuscript on behalf of all authors: Klimo. Statistical analysis: Jones. Study supervision: Klimo.

\section{Correspondence}

Paul Klimo Jr., Semmes-Murphey Neurologic \& Spine Clinic, 6325 Humphreys Blvd., Memphis, TN 38120. email: pklimo@ semmes-murphey.com. 